\title{
AK Mammasonografie schreibt Förderpreis aus - jetzt bewerben
}

Der Arbeitskreis Mammasonografie der Deutschen Gesellschaft für Ultraschall in der Medizin (DEGUM) schreibt auch für 2020 den Förderpreis des Arbeitskreises aus. Der Preis ist mit 500 Euro dotiert und richtet sich an Wissenschaftler der Mammasonografie, die sich mit außergewöhnlichen Publikationen oder einer Habilitationsschrift der Mammasonografie verdient gemacht haben.

Autoren, die bereits den DEGUM-Preis verliehen bekommen haben, können sich nicht ein zweites Mal bewerben. Es ist jedoch möglich, dass eine abgelehnte Arbeit im Folgejahr erneut eingereicht wird.

Der Antrag ist formlos auf elektronischem Weg unter Anlage der Publikation bis zum
15. März 2020 an die DEGUM-Geschäftsstelle (DEGUM e. V., Charlottenstr. 79/80, 10117 Berlin, geschaeftsstelle@degum.de) zu richten.

Die Preisverleihung erfolgt während des Treffens des Arbeitskreises am 9. Mai 2020 in Frankfurt am Main. Die Anwesenheit des Preisträgers ist hierbei obligat. Im Rahmen der Preisverleihung wird der Preisträger bzw. die Preisträgerin aufgefordert, seine bzw. ihre Arbeit in einem Kurzreferat vorzustellen.

Prof. Dr. med. Werner Bader Sprecher Arbeitskreis Mammasonographie

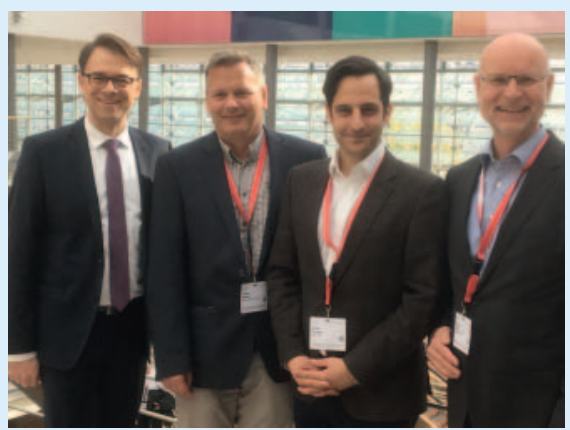

Prof. W. Bader (rechts) und Prof. M. Hahn (links) vom Arbeitskreis Mammasonografie freuen sich, nach erfolgreichen Vorträgen während des Stufe-III-Treffens im Rahmen des 43. Dreiländertreffens in Leipzig PD Dr. med. André Farrokh (2. v. rechts) die DEGUM-Stufe III und Dr. med. James Seabert (2. v. links) den Status des DEGUMStufe-II-Kursleiters zuerkennen zu können. Foto: DEGUM. 